\title{
Family therapy with elderly people
}

\section{Susan M. Benbow \& Alison Marriott}

Those who work with older adults will inevitably find themselves working with families. Indeed assessment of an older person is often difficult if members of their family and social network are not involved. Referrals to social and psychiatric services are often precipitated by family changes. Ratna \& Davis (1984) described 142 consecutive referrals to a community old age psychiatry service and found retirement, family conflict, departure of or illness of a carer, or bereavement precipitated $60 \%$ of referrals. Thus, work with older adults will often necessitate work with families, although it may not be seen in those terms.

\section{A history of family therapy}

Family therapy began to develop in the UK and the USA in the 1950s. Theoretical models were developed in which the family was regarded as a system and contributions to the developing field came from many areas including psychoanalysis, mathematics, cybernetics and communication theory. The family as a system was conceptualised as an entity whose component parts interact and evolve together in ways which maintain the system. Instead of regarding symptoms as a problem for individuals, problems were seen as having a systemic function in maintaining or unbalancing relationship patterns involving individuals. From the shared systemic understanding various schools of family therapy developed ('structural', 'strategic' and 'systemic' models of therapy; see below).

Traditionally, family therapy has probably been used most in work settings with younger families, particularly those with young children or adolescents. There is, however, a growing interest in using family approaches and techniques with older adults. Chronic illness of any sort can send ripples through the extended family, so family work may be as important in work with physically as with mentally ill older adults. Since family support often becomes important as people age, it could be argued that family therapy may be at least as useful in later life as in younger familes.

\section{Family systems therapy}

Jones (1993) defined a system as:

a group of elements in interaction with one another over time, such that their recursive patterns of interaction form a stable context for individual and mutual functioning.

The focus is on the relationships between parts of the system rather than the individuals involved in it. The designation of what consititutes or is involved in the system is a distinction drawn by an observer and is open to other interpretations. Feedback and circularity are important ideas in considering interactions. If A tells B to do something and B does it, then this may affect $A^{\prime}$ s behaviour in future: she may be more likely to tell B to do something. A's actions therefore influence $B^{\prime} s$, but $B^{\prime} s$ response to $A^{\prime}$ 's actions also influences $A^{\prime}$ s future actions. This circularity leads to ideas of positive and negative feedback in interactions between individual family members. Punctuation refers to the way in which an observer selects out particular sequences of interaction. An observer may choose a linear punctuation, such as A tells $B$ to do something and $B$ does it, or a circular punctuation, such as $A$ is more likely to tell $B$ to do something because $B$ has always expected A to make the decisions in their relationship in the past. Circular views of interactions between

Susan Benbow is Consultant Psychiatrist (Old Age Psychiatry) and Alison Marriott is Consultant Clinical Psychologist with Central Manchester Healthcare Trust. Both are registered systemic therapists, members of the Central Manchester Family Service which specialises in working with later-life families and is committed to close working between psychiatry, psychology and other disciplines active in late-life mental health. Correspondence to: SCOPE, Carisbrooke Resource Cenre, Wenlock Way, Gorton, Manchester M125LF. 
individuals can avoid both the attribution of blame and the need for assumptions about initial causes.

These ideas are as relevant to later life as to younger families, perhaps even more so since older people in families will have established patterns of interactions over long periods of time.

\section{Models of therapy}

\section{Structural family therapy}

A structural therapist joins with a family, challenges them and then offers alternative ways of behaving using verbal and non-verbal techniques. Once families have tried out alternative patterns of behaviour new relationships develop which are thought to be reinforcing.

Structural therapists are interested in sub-systems within families, and 'healthy' families are seen to be those in which boundaries between the sub-systems are effectively established. In later life boundaries between sub-systems may change; thus, if there are sub-systems of children, parents and grandparents, when the grandparents become frailer and in need of more support the boundaries may need to be renegotiated to allow for continued family functioning. Sometimes families may seek assistance if renegotiation cannot be achieved by their own efforts.

\section{Strategic therapy}

A strategic therapist aims to remove the power of the symptom in defining family relationships by changing family organisation in a stepwise fashion.

Some have argued that strategic therapy offers a useful problem-solving framework that is more compatible with work in late life since it is shortterm and defines realistic goals (Bonjean \& Spector, 1988). Developed societies may regard older people and older life cycle changes as 'problematic' negative stereotypes of ageing and ageist attitudes may be common. This may fit with a strategic approach.A family may view their situation in coping with an ageing family member and that person's needs as a problem requiring a solution. A solutionfocused therapy may thus offer effective intervention.

\section{Milan systemic therapy}

A systemic therapist aims to change the family's beliefs. Therapist neutrality and teamwork are often intrinsic features.
Roper-Hall (1992) argues that systemic family therapy can provide a way of "co-creating alternative ways of understanding the situation", and is particularly appropriate in later-life work, where referrals may involve illness and/or dependency. Systemic therapy tries to help a family generate their own ways of dealing with a situation and may be particularly appropriate when a family faces a situation which is unlikely to change (e.g. chronic physical or mental illness or the inevitable decline of a dementing illness). If the family members' beliefs and perceptions change, then this may influence how they cope with what is effectively the same situation.

\section{Other family interventions}

Work on expressed emotion (EE), which involves interviewing family members and measuring critical or hostile comments about the identified patient, has led to a psychoeducation model of intervention. For example, Barrowclough \& Tarrier (1992) describe an intervention model for people suffering from schizophrenia and their families. This approach emphasises the importance of family interactions and family responses to the well-being of individuals with serious mental health problems in terms of relapse prevention and high EE. This approach could be considered for families with high levels of EE who are struggling with chronic or recurrent illness in older family members.

\section{Family therapy applied to older adults and their families}

The techniques/ideas selected here are a few of those core family therapy ideas which can be useful in everyday practice with older adults. They may not necessarily be the most important but can nevertheless be influential outwith the family therapy clinic.

\section{The family life cycle}

The family has a life cycle, as does an individual. One model divides family development into six stages of which five cover the period from single adulthood to launching children and one final stage is seen as spanning retirement until death of both partners (Table 1) (Carter \& McGoldrick, 1989). This model is unbalanced since the final stage could, with shorter periods of child-bearing, early 


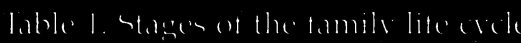

Family life cycle stage Key issues

$\begin{array}{cc}\begin{array}{c}\text { Leaving home: single } \\ \text { young adults }\end{array} & \begin{array}{c}\text { Accepting responsibility } \\ \text { for self; independence }\end{array} \\ \begin{array}{c}\text { Joining families } \\ \text { through partnership: } \\ \text { the young couple }\end{array} & \begin{array}{c}\text { Commitment to a new } \\ \text { family; negotiation }\end{array} \\ \begin{array}{c}\text { Families with young } \\ \text { children }\end{array} & \begin{array}{c}\text { New members join the } \\ \text { system }\end{array} \\ \begin{array}{c}\text { Families with } \\ \text { adolescents }\end{array} & \begin{array}{c}\text { Flexibility of boundaries } \\ \text { to allow growing } \\ \text { independence; ageing of } \\ \text { grandparents }\end{array} \\ \begin{array}{c}\text { Exits from family and } \\ \text { moving on }\end{array} & \begin{array}{c}\text { renegotiation of } \\ \text { partnership; 'empty nest' } \\ \text { Later life family }\end{array} \\ \begin{array}{c}\text { Shifting of generational } \\ \text { roles }\end{array}\end{array}$

retirement and extended life expectancy, cover as many years as the first five. This imbalance could imply that the later stages of the family life cycle involve fewer developmental tasks.

However, later stages of family life involve many adjustments. One partner may retire first, followed by the second. Illness and disability of family members may occur. For older family members their roles as grandparents may involve different forms of child care and support of their own children, now themselves parents. Many people may become greatgrandparents, with implications for all generations of the family. Loss of their peers may occur, and loss of the status associated with younger adulthood and paid employment. Eventually one partner dies and the surviving partner faces additional social restrictions associated with widowhood.

Later family development may involve parents accepting the need to depend on others including their children, and adult children accepting that parents may need to accept help from and to depend on them. Attachment theory can be seen as important here. Adult children may anticipate parental decline by taking on care-giving before help is actually needed, or feel stressed despite providing little or no help. Perceived parental dependency may relate to negative feelings more than the amount of practical help given.

An understanding of later life cycle issues can be vital to an understanding of the difficulties experienced by older adults referred to services. It also helps professionals to take a more holistic and comprehensive approach to care as the individual will be treated within the context of the stage of life they have reached, and the life cycle issues which other family members are facing will also be taken into account.

\section{Cross-generational interplay of life cycle problems}

When one generation faces an important life cycle transition, another generation of the same family may be facing its own transition point. If the needs of the two generations are incompatible there is lack of 'complementarity' or 'fit'.

The family life spiral is another way of looking at this (Fig. 1). At some times in family development family members are closely involved with one another (e.g. during times of childbirth and death). At others family members are orientated more towards interests outside the family (e.g. during adolescence, the 40 s and early retirement). If one generation is passing through an outwardlooking phase when another seeks closeness, tensions may arise (Combrinck-Graham, 1988).

When working with older people their families may often be facing these tensions. For example, a person's expectations of retirement may not accord with their partner's or children's expectations. The older person may look forward to more time at home, more freedom to pursue interests or more boredom.Their partner may anticipate more help with their own tasks, more companionship or more closeness. Adult children may expect more help with babysitting, more visits, more time together as a family. There may be marked differences between the expectations of different generations, and in expectations of care, which may lead to conflict and/ or disappointment among family members.

\section{Genograms}

The use of a genogram or family tree is an economical way of collecting, organising and storing information (Fig. 2). Although genograms may be regarded as a distinctive feature of family therapy they can be used in routine practice and can be a useful part of case notes.

Many older people who have had long-standing illnesses will have enormous case files with information buried deep within them. A genogram can be used to summarise family information and to highlight important landmarks, illnesses etc. This can also be a useful tool in general practice.

\section{Circular questions}

Circular questions aim to gather information by asking questions in terms of differences and hence 


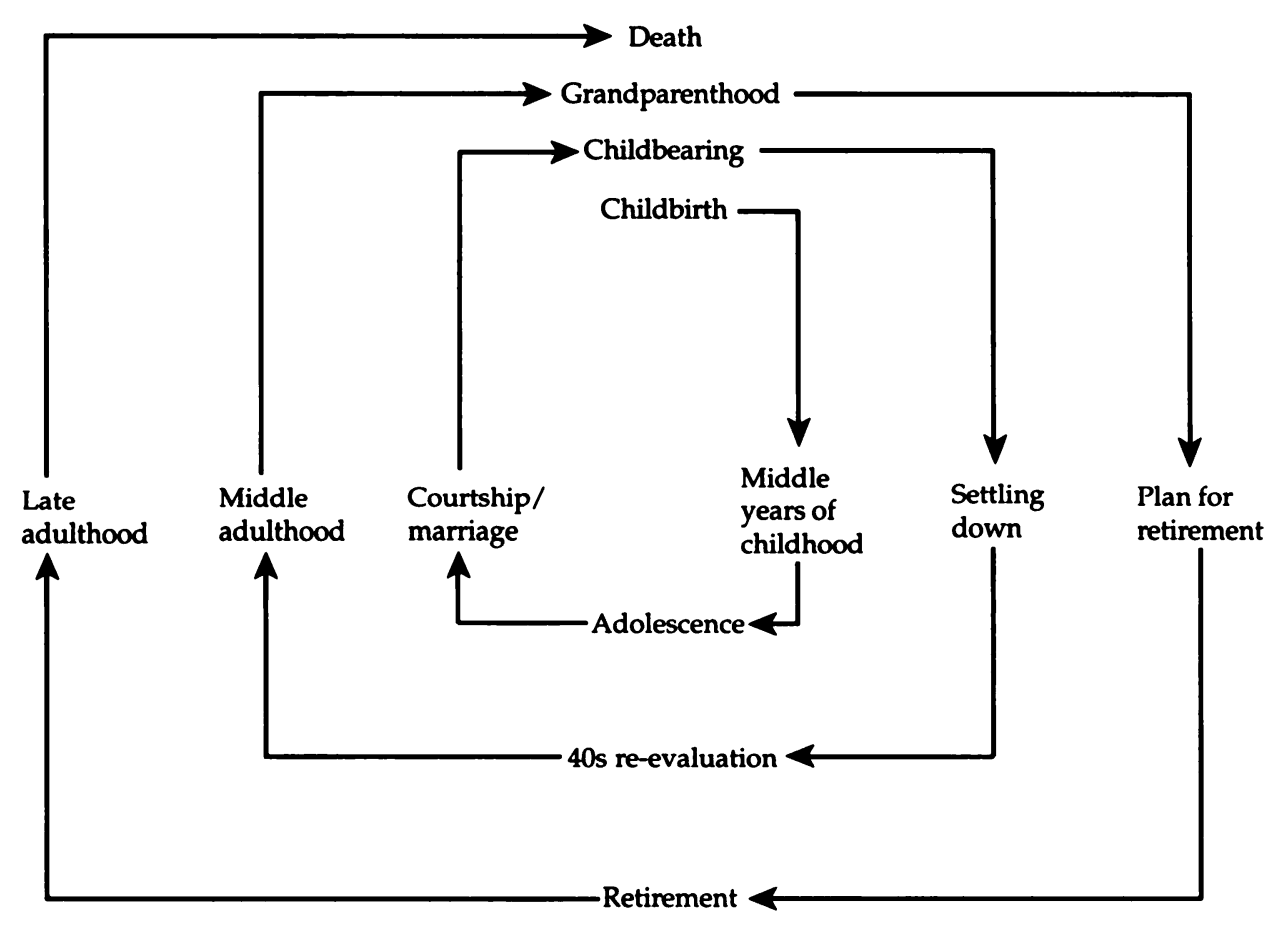

\section{Fig. 1 Family life spiral}

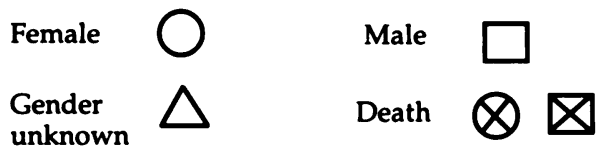

Index person or client

(O)

Married couple

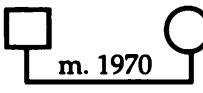

Other partnership<smiles>CC1CCC12CCC2</smiles>
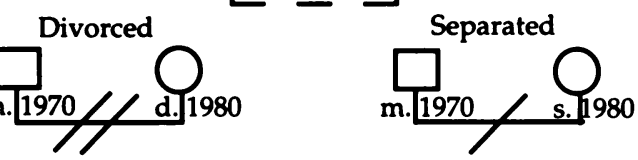

Couple with one son and two daughters in birth order
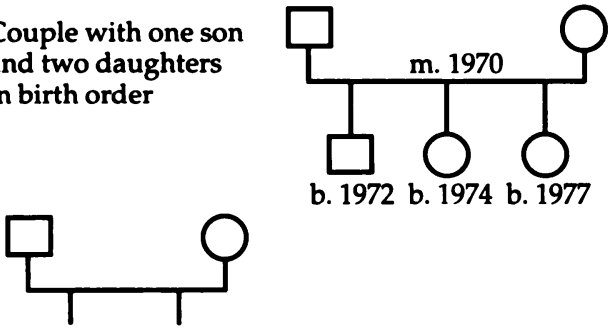

b. 1972 b. 1974 b. 1977

1 Adopted or foster children

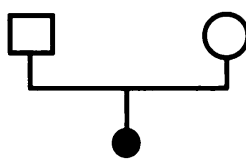

Miscarriage

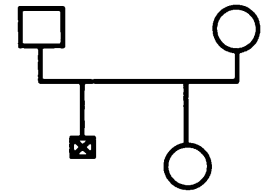

Stillbirth

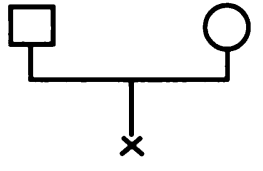

Induced abortion

Genogram for Mrs M.

(see case history)

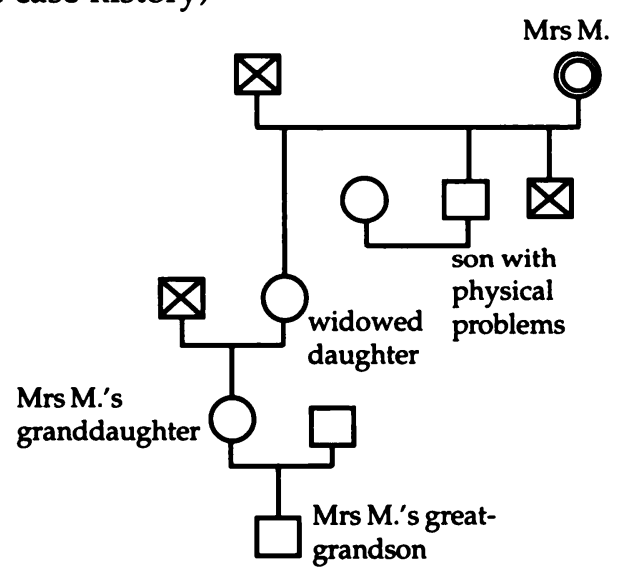




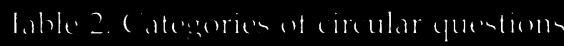

\begin{tabular}{|c|c|}
\hline Category & Description \\
\hline Sequential & $\begin{array}{l}\text { Enquire about specific behaviours in } \\
\text { specific circumstances }\end{array}$ \\
\hline Action & $\begin{array}{l}\text { Enquires into differences indicated } \\
\text { by behaviour }\end{array}$ \\
\hline Classification & Allows ranking of family responses \\
\hline Diachronic & $\begin{array}{l}\text { Investigates changes in behaviour } \\
\text { indicating changed relationships at } \\
\text { two time points }\end{array}$ \\
\hline Hypothetical & $\begin{array}{l}\text { Investigates differences in opinion } \\
\text { regarding imagined situations }\end{array}$ \\
\hline Mind reading & Examines communication in a family \\
\hline
\end{tabular}

of relationships. Table 2 summarises the six main categories of questions. In therapy the questions are linked with systemic hypotheses, but they are thought-provoking questions which can have a role in day-to-day work with families. They help professionals (and family) to understand the relationships between family members, how they perceive one another and what their expectations of services and change are. At an initial home assessment visit it can be useful to ask a referred person what they were hoping for from the assessment and what they think various important others were hoping would come from it.

\section{Reflecting teams}

Tom Andersen and coworkers developed the use of reflecting teams (Andersen, 1992). Originally this involved team members talking about their ideas regarding a family while the family and therapist listened. It can be seen as an extension of Bateson's concept of double description which Jones (1993) describes as:

obtaining more than one view of an event (which) would enable us to achieve the cognitive or emotional equivalent of binocular vision, thus gaining, in a metaphorical sense, perspective on our observations and experiences.

It carries with it an expectation of openness between family and professionals and a change in the balance of power.

This model fits too with the way many multidisciplinary teams work by drawing on the ideas and contributions of various team members with different perspectives rather than relying solely on
Examples

When your mother says she will never go into a Home, what does your brother do?

What does your mother say or do that makes you say she is confused?

Who in the family most thinks that putting your mother in a Home will solve the problem?

Did Frank and your mother get close before or after your father died?

Suppose your mother decided to go into a Home, whose life would change most in the family?

If your father were still alive today what would he think about your mother going into a Home?

the most articulate, most senior or loudest team members.

\section{Family therapy with older adults}

Formal family therapy is used with older adults and their families in a number of centres around the UK. It is used with functional psychiatric illness, with organic brain syndromes and in those with chronic physical illness.

\section{Functional psychiatric illness}

We use family therapy with families where functional illness leads to their contact with the service, often utilising family therapy alongside other therapeutic activities (Benbow et al, 1990).

\section{Case history}

Miss E., a single woman of 74 years old, presented with an agitated depressive illness with marked biological symptoms. She lived with her sister and brother-in-law and had retired at 64 . Their mother was described as having melancholia and two sisters had had psychiatric treatment. After initial assessment at home, antidepressive drug treatment was started but Miss E. deteriorated, appeared to be 'confused' and was admitted to in-patient care. On the ward the antidepressives were cut down and she appeared well. After successful home leave she was discharged but within three days became severely depressed with ideas of guilt, hopelessness and 
worthlessness. She went to a local reservoir intending to drown herself, but was taken home by a neighbour and readmitted. After a short course of ECT she was mildly elated, but stabilised and was discharged home on maintenance drug treatment. Her symptoms started to reappear within two weeks and she was readmitted depressed, suicidal and psychotic six weeks after discharge. On the ward she soon improved. A formal family meeting was arranged with Miss E., her sister and brother-in-law.

In conversation it emerged that the two sisters had always been close and in some ways her sister had always parented Miss E. Her brother-in-law's forthcoming redundancy had caused worry for all three family members and before her illness started Miss E. had become more independent (e.g. buying a piano).

Team hypotheses included the following:

(a) Was Miss E.'s 'growing up' allowing space for her sister and brother-in-law to become a married couple?

(b) Was Miss E.'s illness keeping her sister from worrying about her husband's redundancy and their future relationship?

(c) Was Miss E.'s depression keeping her sister busy and well (since her sister too had a history of depression)?

All three family members were facing important transitions: what conflicts were there between their needs?

This initial meeting led on to a series of 12 meetings during which Miss E. decided to move into a residential home and eventually her sister and brother-in-law were seen several times as a couple. They appeared to become closer over time, although both found losing Miss E. difficult. Miss E. settled in to her chosen residential home quickly, made new friends, limited her visits to the family to once weekly and started to do things she had not done for years (e.g. going to town on the bus shopping). When contacted for follow-up by telephone some months after the final session, her sister and brother-in-law had found new interests and become more involved with other family members, as well as continuing weekly contact with Miss E.

\section{Organic brain syndromes}

Family therapy has been used in a number of settings with families whose members suffer from chronic illness. Dementia is one chronic illness with repercussions for the whole family. We have reviewed our experience in this area (Benbow et al, 1993). We commonly involve the cognitively impaired family member in family meetings and often see families for a small number of sessions stretched out over a fairly long time course, sometimes years, as they struggle to adjust to the dementia sufferer's decline. The issues discussed are often similar to those discussed in families coping with functional illness and we use the same approach or range of techniques in working with them. Feedback to date is generally positive, although we are still evaluating outcome. We believe that the relationship between family and psychiatric service is more collaborative overall using this approach.

\section{Case history}

Mrs M., a widow in her 90s, lived with her widowed daughter and presented with cognitive impairment and some depressive symptoms. Her daughter felt stressed and anxious caring for her mother, who was a strong-minded, independent woman, reluctant to accept help from outside the family. She had a married son with long-standing physical health problems and another son had died. Over a period of several years Mrs M., her daughter, daughter-in-law, son, granddaughter, granddaughter's husband and great-grandson in various combinations met on several occasions to negotiate together how to support Mrs M. and her daughter and to discuss how the whole family had been affected by her illness. Eventually Mrs M. moved into a residential home as her health deteriorated, but the family meetings, although separated by a number of months, appeared important in negotiating her care in the community for several years.

\section{Family therapy within the wider psychiatric services}

Our interest in family therapy has had effects throughout the old age psychiatry service.

\section{Community service}

Where the family/members of the support system have not been seen, it could be argued that assessment of the older person is incomplete. The reason for referral may be related to family changes or perceptions rather than changes in the medical/ psychiatric state of the older person. Thus, community staff may be more likely to involve family/other supporters throughout their contact with older people in services which take a family therapy approach.

Sometimes community visits by individual staff members may be met by groups of family members concerned about their older relative. It is helpful 
to be able to draw on family therapy training and ways of understanding which act as resources in dealing with situations like this and which may help us as professsionals to consider alternative ways of dealing with difficult situations. One particularly difficult situation can be when family members are more concerned about a situation than the older person themself is.

\section{Day hospital}

We have involved family/other supporters in review meetings in the day hospital since our involvement in family therapy. There is a balance between the need for openness and family involvement and the perceived right of the patient to confidentiality with regard to details of their illness. This can be an area of potential conflict but if we perceive our role as one of helping the whole family, rather than an individual in isolation, this can alter the openness/confidentiality balance. Being clear where we stand in relation to this will help us to address the dilemma with family members where there are particular problems.

\section{Hospital wards}

Involvement of family members throughout an admission can be very difficult and time-consuming in practice, so often one member of the old age psychiatry team will need to act as primary liaison with the family. Sometimes formal family meetings may be arranged while an older adult is on the ward. On one ward we involve family/other carers in meetings with the staff team prior to making discharge decisions or arrangements.

\section{Case history}

Mr R., aged 66, was admitted after a serious suicide attempt failed. He gave a history of depressive illness following unwelcome retirement on admission, but within a few days of his arrival on the ward he claimed to be back to his normal self and he and his family requested early discharge home. A family meeting was arranged in the family clinic and attended by Mr R., his wife, one son and daughterin-law. All those present discussed the suicide attempt, events leading up to it and ways to help $\mathrm{Mr} \mathrm{R}$. adjust to his new lifestyle as a retired person. The family worked out with the therapists how they would like discharge to take place and what ongoing support/follow-up might be helpful and for whom. The relationship between team and family changed from one of suspicion and mistrust to one of collaboration in working towards shared goals.

\section{A formal family clinic}

We also run a formal family clinic which takes place weekly in a resource centre about 1.5 miles from the hospital. The clinic is staffed by a multidisciplinary team including community nurses, medical staff, psychologists, nurses from other settings (especially day hospital), social workers and occupational therapists. Families are seen for about 1-1.25 hours by two therapists, and the rest of the team act as a consulting team, offering reflections to the therapists before and after the meeting and during a short intermission before the family meeting closes. We have found that the use of co-therapists allows us to be open and creative with families. We usually work with a mixed-gender co-therapy team.

A video link allows the team to watch and listen to family sessions and we usually (when the family agrees) make a recording of the session.

\section{Outcome and effects of family therapy}

The study of outcome in family therapy is problematic. Controlling studies can be difficult and outcome measures are not well established, particularly when working with a family coping with a terminal illness such as a dementia. We have used team consensus ratings (Benbow et al, 1993) but these are blunt instruments and open to observer bias. We have also experimented with asking families to rate the outcome of their contact with the clinic. This can also be difficult to interpret because families where the team rate the outcome as 'considerably helped' have sometimes expressed the view that they have not been helped at all since the eventual outcome has not been the one which individual members of the family were originally hoping for. An example would be where a son wanted to move in with his mother and care for her, but they both decided after meetings in the clinic that she should move into a residential home. Part of the work with the family would perhaps be to consider for whom and how this was a good outcome, but ratings made by the family may be coloured by the difference between outcome and original intent.

Currently we are looking at how to combine therapist/team ratings with family ratings. Another approach would be to agree with the family at the outset what they are looking for from the family clinic, in order that family and therapists can then look back at how goals have been met. The area of work may, however, evolve as the family are seen over time, so that initial goals may not always be relevant at the end of therapy. 


\section{References}

Andersen, T. (1992) Reflections on reflecting with families. In Therapy as Social Construction (eds S. McNamee \& K. J. Gergen), pp. 54-68. London: Sage.

Barrowclough, C. \& Tarrier, N. (1992) Families of Schizophrenic Patients: Cognitive Behavioural Intervention. London: Chapman \& Hall.

Benbow, S. M., Egan, D., Marriott, A., et al (1990) Using the family life cycle with later life families. Journal of Family Therapy, 12, 321-340.

-, Marriott, A., Morley, M., et al (1993) Family therapy and dementia: review and clinical experience. International Journal of Geriatric Psychiatry, 8, 717-725.

Bonjean, M. \& Spector, R. (1988) Empowering the elderly. Networker, July/August, 25-29 \& 76-79.

Carter, B. \& McGoldrick, M. (1989) Overview: the changing family life cycle - a framework for family therapy. In The Changing Family Life Cycle - A Framework for Family Therapy (2nd edn), pp. 3-28. London: Allyn \& Bacon.

Combrinck-Graham, L. (1988) Adolescent sexuality in the family life spiral. In Family Transitions: Continuity and Change over the Life Cycle (ed. C. J. Falicov), pp. 107-131. London: Guilford Press.

Jones, E. (1993) Family Systems Therapy Developments in the MilanSystemic Therapies. Chichester: John Wiley \& Sons.

Ratna, L. \& Davis, J. (1984) Family therapy with the elderly mentally ill. Some strategies and techniques. British Journal of Psychiatry, 145, 311-315.

Roper-Hall, A. (1992) Better late than never? Family therapy with older adults. Clinical Psychology Forum, October, 14-17.

\section{Multiple choice questions}

1. Which of the following statements about family therapy techniques are true:

a the family life cycle emphasises the important development tasks of later life

b the genogram is a useful way of summarising information about a family

c circular questions involve asking the same question of several different family members

d reflecting teams are therapy teams separated from the family by a one-way mirror

e these techniques can only be used in formal family therapy clinics.
2. Family therapy with other adults:

a can be used alongside other psychiatric treatments

b is contraindicated by a diagnosis of dementia

c may raise questions regarding confidentiality

d may involve a small number of meetings over a long period of time as families adjust to chronic illness

e helps professionals to take a holistic approach to care.

3. Family therapy:

a may be helpful in working with families coping with chronic physical illness in later life

b has clearly established outcome measures

c using a systemic approach aims to change family members' beliefs

d can use a psychoeducational model to try to reduce levels of emotional expressivity

e can help families to generate their own ways of dealing with a situation.

4. Within a psychiatry service:

a family therapy training is useful for staff meeting with families in the community

b family therapy ideas can have effects throughout the service

c in-patient care is not compatible with formal family therapy

d family therapy can alter the relationship between professionals and families

e family therapy should be evaluated and audited.

\begin{tabular}{ccccc}
\multicolumn{6}{l}{ MCQ answers } & & \\
1 & 2 & 3 & 4 \\
a F & a T & a T & a T \\
b T & b F & b F & b T \\
c F & c T & c T & c F \\
d F & d T & d T & d T \\
e F & e T & e T & e T
\end{tabular}

